\title{
The Socio-Ecological Dynamics of Human Responses in a Land Degradation-Affected Region: The Messara Valley (Crete, Greece)
}

\author{
Vassilis Detsis $^{1, *}\left(\mathbb{D}\right.$, Helen Briassoulis ${ }^{2}$ and Constantinos Kosmas ${ }^{3}$ \\ 1 Laboratory of Human Ecology \& Agricultural Economics, Harokopio University, 17176 Athens, Greece \\ 2 Department of Geography, University of the Aegean, 81100 Mytilini, Lesvos, Greece; e.briassoulis@aegean.gr \\ 3 Laboratory of Soils, Agricultural University of Athens, 11855 Athens, Greece; ckosm@aua.gr \\ * Correspondence: detsis@hua.gr; Tel.: +30-210-9549351
}

Academic Editor: Artemi Cerdà

Received: 10 April 2017; Accepted: 20 June 2017; Published: 26 June 2017

\begin{abstract}
This paper applies a resilience- and assemblage-based methodology to study the socio-ecological dynamics of human responses in the land degradation-affected Messara Valley (Crete, Greece) socio-ecological system, from 1950 to 2010. It posits that thesedynamics aredriven by changes in their effectiveness, called 'socio-ecological fit', to serve place- and time-specific goals. The socio-ecological fit expresses the degree to which the match among all the biophysical and human components of a Response Assemblage emerging in a socio-ecological system, maintains the socio-ecological resilience of this Assemblage. The socio-ecological resilience results is gauged by synthesizing three system-level properties (Resilience, Adaptability, Transformability) shaped by lower level properties that are assessed from available data. The reported application revealed that human responses (traditional land management, agricultural modernization and subsidized agriculture) and their effectiveness were driven by prioritizing economic and technological considerations that shaped the properties, socio-ecological resilience and fit of three main Response Assemblages formed over the study period, rather than combating land degradation. Agricultural modernization did not uniformly and necessarily lead to land degradation; the situated relationships among the components of the Response Assemblages determined its effects. The fit of future options can be assessed also to support rational land use planning. Refinements in the methodology include the development of techniques to: (a) assess and synthesize the properties of different components in order to improve assessments of socio-ecological resilience and fit and (b) study relationships among the properties of Response Assemblages emerging at different levels.
\end{abstract}

Keywords: land degradation; human responses; assemblage; socio-ecological resilience; fit; socio-ecological system

\section{Introduction}

Human responses to land degradation (LD) assumedly aim at alleviating adverse impacts on biophysical and human resources, thus, preserving critical ecological and human functions and securing the sustainable development of affected socio-ecological systems (SES). A vast literature underlines their importance and the strong policy interest in their effectiveness, in general, and in 'best practices' in particular [1-3]. There is a growing awareness, also within specialized scientific disciplines, that relevant research cannot be conducted anymore in isolation. On the key issue of soil, calls have been made to the research community to increasingly engage in transdisciplinary studies, involve stakeholders and improve communication and engagement in policy making if the field is to successfully contribute towards the achievement of the sustainability goals set in the frame of UN 
Conventions $[4,5]$. The reason is that soil management decisions taken by farmers are influenced by a large number of factors, sometimes operating even at a global scale.

Human responses to LD are usually narrowly conceived as specific remedial actions (henceforth, response options) targeting either the resources impacted and/or the drivers and proximate causes of LD. These include sustainable land management, environmental legislation, economic incentives and customary rules, among others. The Millennium Ecosystem Assessment [6], however, defines human responses as any type of action, planned (formal, institutionalized) or unplanned (informal, non-institutionalized), originating in various spatial levels from the local to the global, that purports either to directly tackle a LD problem or to address other socio-economic problems as well as individual and collective goals in affected regions. This broader definition reflects the understanding that LD and human responses are outcomes of complex, multilevel, place- and time-specific interactions between the biophysical and human components of a SES, encompassing response options as practiced in a given socio-spatial context, over time that aim to achieve various goals which may include combating LD [7]. Briassoulis [8] has suggested that it is preferable to conceptualize human responses as response assemblages (RAs), defined as "geographically and historically unique, provisional, open, territorial wholes, complex compositions emerging from processes of assembling biophysical and human components from an affected focal and other SESs, to serve human goals. Characteristic land use profiles, human responses and particular responses to degradation mark their identity. RAs operate at multiple overlapping spatial scales and interact with each other, both as distinct entities and through the cross-level relationships of their constituents." ([8], p. 1449).

The effectiveness of response options to combat LD and produce desirable socio-economic impacts is judged by their ability to maintain the socio-ecological resilience of the affected SES, i.e., its capacity to respond to disturbances and reorganize, while undergoing change, so as to preserve its identity, structure, critical functions and feedbacks in ways that do not foreclose future development options $[9,10]$. This effectiveness depends on the match of response options to the socio-ecological context where they are practiced. The assumption is that the greater this match, the more resilient a SES is to shocks [10-13]. This is defined here as the socio-ecological fit (SEF) of responses to LD. The effectiveness of human responses conceived more broadly as RAs depends on the match among all SES components comprising an RA. This is defined here as the socio-ecological fit of the RA (SEFRA). SEFRA is broader and more inclusive than the narrower SEF which focuses on the socio-ecological fit of particular response options only [8].

If the match between response options and/or SES components produces desirable outcomes, as perceived by particular stakeholders at least, i.e., they help combat LD and promote sustainable development, the responses are considered positive and well fit to the particular geographical and historical setting, while the response assemblage is judged to be socio-ecologically fit for the purpose of combating LD. Otherwise, the response options and/or SES components may be modified to improve effectiveness under changing exogenous and endogenous biophysical and socio-economic conditions. The main thesis of this paper is that the socio-ecological dynamics of human responses in a SES, i.e., their emergence and evolution, is driven by changes in their effectiveness (socio-ecological fit) to serve human purposes at particular places and times that reflect changes in the socio-ecological resilience of the emergent RAs. One question that arises concerns the choice of a suitable approach to study this dynamics to support rational decision making and land use planning to combat LD. This paper outlines a conceptual and methodological approach towards this purpose, illustrates its use in the case of the Messara Valley (Crete, Greece) SES, evaluates its usefulness for decision making and identifies future research challenges.

\section{Conceptualizing the Socio-Ecological Dynamics of Human Responses to Land Degradation}

The understanding that human-environment interactions, such as land degradation and human responses to LD, are contextual and contingent has led to a shift from earlier linear, uni-disciplinary, uni-dimensional and reductionist to nonlinear, interdisciplinary, integrated and less reductionist 
approaches to the analysis of coupled socio-ecological systems that broadly aim to support sustainable development decision making [8]. These approaches variously conceptualize, operationalize and treat issues of environment, economy, society, decision making, and of horizontal and cross-level interactions among SES components. They commonly emphasise the thorough description of the focal SES and its dynamics, adopt socio-ecological resilience (SER) as a measure of system performance and use scenario approaches to treat future uncertainty and different actor perspectives.

The focal SES is usually conceptualized as a seamless whole, comprising biophysical and socio-economic components linked by relationships of interiority (logically necessary, which make wholes what they are) [14], which follows an evolutionary path. Alternatively, the focal SES and its socio-spatial hierarchy can be conceptualized as a multiplicity of assemblages that emerge from processes that assemble heterogeneous elements into provisional, historically unique compositions (individual singularities) to serve a purpose. Response assemblages, more specifically, are composed of economic, socio-cultural, institutional, political and other components, of variable spatio-temporal reach and membership, which include various types of response options. Their relatively autonomous components are linked by relationships of exteriority (contingently obligatory over some time interval) $[8,15]$. Territorialization/coding processes (habitual, routine practices such as resource use, communication and cooperation, governance procedures, etc.) assemble and hold the components together. Deterritorialization/decoding processes (e.g., natural, socio-economic, policy change, etc.) disassemble and reassemble them. Historic contingencies and empirically identified mechanisms determine the RAs that eventually emerge [14,16].

RAs possess properties that are not the sum of the properties of their components but emerge from contextual and contingent, complex interactions among components, especially the critical ones, i.e., those associated with critical biophysical and human functions, which exercise their capacities;i.e., powers they possess, regardless of whether these are exercised or not, which are tentatively predictable at best $[14,17]$. The set of possible capacities of the critical components constitutes the possibility space of the assemblage, i.e., the phase (or, state) space of complex systems. The number of critical components determines its dimensions (degrees of freedom) [14,16]. A basin (or, domain) of attraction is a region in the possibility (state) space defined around an attractor; i.e., a minimum state towards which a large number of different trajectories of the SES (made up of assemblages emerging during its evolution), starting from some point in the basin, tend [17]. Attractors represent patterns of behavior and reveal the tendencies of an assemblage [16,17].

The geometry of a basin and the position of an actual RA within it (i.e., a point in the basin representing a state of the SES) is described by its latitude (L)—denoting the maximum change the system can endure before losing its ability to recover; resistance (R)-denoting the ease or difficulty of changing the system; precariousness (Pr) - the proximity of the system to a threshold which, if breached, makes recovery difficult or impossible; panarchy (Pa) - the influence of factors from levels above and below the focal level [18]. The critical components, which usually change more slowly than other components, control the geometry of a basin. The SES remains within and moves about the basin for a certain period, changing states as it adapts to changes in its components, disturbances, contingencies, etc. If thresholds of critical components (e.g., soil depth, population size, socio-cultural acceptance) are crossed, the SES moves to a different basin with different characteristic RAs [14,16,17]. Complex SESs have complex distributions of attractors and multidimensional basins of attraction populated by RAs emerging from different combinations of their components and governed by the inherent capacities and thresholds of critical components while they interact producing or reducing land degradation under particular historical contingencies.

The socio-ecological resilience (SER) of an RA is a hyper-property of a SES which, according to the resilience literature, can be expressed through three system level properties; namely, Resilience, Adaptability and Transformability (RAT in short). Resilience is the capacity to absorb disturbance and reorganize while undergoing change so as to still retain essentially the same functions, structure, identity, and feedbacks. Adaptability or adaptive capacity is the ability to cope with novel situations 
without losing options for the future; or else, the capacity of actors to manage, intentionally or unintentionally, resilience. This can be achieved either by affecting the geometry of the basin of attraction [18] and/or by affecting the position of the SES within the basin, i.e., by modifying the actual RA. Finally, Transformability is the capacity to create a fundamentally new system when the existing system is untenable [9,18-20] or else, the ability of actors to affect a transition, i.e., to actively channel change towards a new basin of attraction.

Resilience, Adaptability and Transformability cannot be directly assessed; they are revealed from the values of apposite lower-level properties (LLPs) of the RA;i.e., from place- and time-specific interactions among and within the biophysical and human components, especially the critical ones. The resilience literature suggests the following important lower-level properties: potential available for change (potential, for short), robustness, diversity, redundancy, connectedness, modularity, openness [18-22]. Based on this literature, Table 1 below provides indicative definitions of these LLPs. The operationalization of each LLP depends on the SES component considered, the state-of-the-art and the availability of data and other resources in a study.

Table 1. Indicative definitions of Lower Level Properties (LLPs). Based on [23-29].

\begin{tabular}{|c|c|}
\hline Potential Available for Change (Potential) & $\begin{array}{c}\text { 'Amounts' of Natural and Human Resources } \\
\text { Available in a SES within a Period That Determine } \\
\text { the Range of Options Possible }\end{array}$ \\
\hline Robustness & $\begin{array}{c}\text { The strength of a system and its elements to } \\
\text { withstand disruption without suffering degradation } \\
\text { or loss of function }\end{array}$ \\
\hline Diversity & $\begin{array}{l}\text { Variety, balance, disparity of components, responses, } \\
\text { ecosystem services, etc. }\end{array}$ \\
\hline Redundancy & $\begin{array}{c}\text { The extent to which a system or its elements have } \\
\text { substitutes to ensure functioning in the event of } \\
\text { disruption }\end{array}$ \\
\hline Connectedness (external, internal) & $\begin{array}{l}\text { Nature and strength of linkages among the } \\
\text { components of a system (positive/negative } \\
\text { feedbacks) on the same and across spatial levels }\end{array}$ \\
\hline Modularity & $\begin{array}{c}\text { Organization of SES components into groups. } \\
\text { Within-group are stronger than between-group } \\
\text { linkages }\end{array}$ \\
\hline Openness & $\begin{array}{c}\text { Degree to which a SES interacts with higher and } \\
\text { lower levels. }\end{array}$ \\
\hline
\end{tabular}

Resilience is mostly related to potential, robustness, redundancy and connectedness/openness, Adaptability to potential, diversity, modularity, connectedness and openness while Transformability to potential, diversity, connectedness and openness [8]. Summing up, it is proposed that lower level interactions among RA components shape its LLPs that, consequently, determine RAT and eventually SER, an emergent RA hyper-property.

When human responses are conceptualized as RAs, the socio-ecological fit of an RA (SEFRA) expresses the degree to which the particular composition and the recurrent processes of assembly of the RA components, as well as their capacities, thresholds and ability to be causally related, promote the preservation of SER within a period. The relative autonomy of the components implies that the existence and degree of fit is contextual and contingent subject to changes in components and/or their contingently obligatory relationships. Consequently, SEFRA is an emergent, distributive and composite trait of the RA, with nonlinear causal structure.

Based on the above, the socio-ecological dynamics of human responses to LD is conceptualized as follows [8]. Human responses (including specific response options) modify the composition and the processes of assembly of the current RA (old components cease or are modified, new ones are added, 
routine processes are modified or replaced by new ones, etc.). Thus, the SES changes states (different RAs emerge) within the current basin of attraction which produce environmental and socioeconomic impacts; i.e., they modify the biophysical and human system characteristics and impinge on critical ecological and socio-economic functions. The interactions among the (modified) components change the LLPs and, consequently, R, A, and T and SER. If SER is above a scientifically and / or socio-culturally acceptable level, the current fit of the RA and of particular response options, i.e., SEFRA and SEF, are deemed satisfactory, the responses desirable and this explains why they persist; or else, the RA remains within the current basin of attraction. The greater the degree of fit (more components match harmoniously), the greater the coherence, stability and durability of the RA. If exogenous forces/contingencies and/or endogenous changes bring some critical components close to a threshold and the associated critical functions are negatively affected, SER drops below an acceptable level, SEFRA and SEF are deemed unsatisfactory and the current RA has a poor fit. At some point, the SES may cross one or more thresholds and move to a basin governed by a degraded state (attractor) and populated by different RAs. Alternatively, social actors may decide to move to non-degraded states, by modifying responses and the current RA, thus, triggering new rounds of the process.

Based on this conceptual approach, [8] developed an integrated methodology to assess SEFRA that comprises four stages: (a) General description of the SES; (b) Evolution of the SES; detailed description of phases; (c) Analysis of SER and SEFRA in each phase; (d) Design of Optimal Response Assemblages (ORA) and Guidance. The first stage thoroughly describes the characteristics of the components of the SES, and selected characteristics of higher and lower level SESs, over the entire study period with adequate temporal detail to reveal (a) the main features ( $\mathrm{L}, \mathrm{R}, \mathrm{P}, \mathrm{Pa})$ of the basin (or, basins) of attraction that characterized the SES, (b) critical/limiting biophysical and/or human variables and any thresholds that have been or may be reached or crossed, (c) other important variables and contingencies. The second stage details the evolution of the SES; i.e., (a) identifies and describes the main phases of the SES (state and transition periods), the characteristic RAs formed in each phase, their composition and processes of assembly, critical components (and any thresholds) and, thus, determines the place of the RA within the basin of attraction and assesses the size of disturbance the SES may (or might) be able to absorb;i.e., its Resilience, prevailing contingencies, higher level responses (e.g., national policies, international agreements, etc.), and (b) assesses the relationships among components (e.g., environmental and socio-economic impacts of human responses) to examine how they have affected the preservation of critical environmental and socio-economic functions. The delimitation of the different states of the SES during a study period draws on [30] that prioritize identity as a key property of a SES and provides the guiding principle for the choice of criteria (e.g., biophysical, socio-economic, land use/landscape) to distinguish the phases of the SES.

The third stage concerns the assessment and explanation of SER and SEFRA in each phase, following the procedure outlined above. This includes: assessment of LLPs, RAT as a synthesis of selected LLPs, SER as a synthesis of RAT, SEFRA and explanation of the transitions between phases and the associated changes in human responses. The fourth stage concerns the design of interventions that may improve SEFRA, i.e., enhance the socio-ecological resilience of the SES, under trend continuation and alternative future scenarios for various types of stakeholders, by following the assessment procedure on the reverse. This indicates RA components and processes of assembly that should be modified or eliminated and/or new ones that should be added. Different assessments of SEFRA under alternative scenarios will suggest different new RAs, named Optimal Response Assemblages (ORAs). Policy and management recommendations can be elaborated to support the emergence of ORAs [8].

The particular assessment techniques used at each stage depend on available resources (data, knowhow/expertise, time, personnel). A large collection of relevant available techniques can be found in the Land and Ecosystem Degradation and Desertification Response information System (http://leddris.aegean.gr/ses-parameters.html). Moreover, several theories from the natural and the 
social sciences should be synthesized to provide holistic explanations of the RAs formed and their evolution over a study period [31]

\section{Human Responses in a Land Degradation-Affected Region: the Messara Valley Socio-Ecological System, 1950-2010}

The socio-ecological dynamics of human responses in the land degradation-affected Messara Valley SES (Crete, Greece) over a 60-year period is briefly presented to illustrate the application of the proposed conceptual approach and integrated methodology. Quantitative and qualitative data were obtained from secondary sources (Hellenic Statistical Authority, other official statistical sources and reports, grey literature), interviews with locals and regional/local level officials and field observations (see also [32]). Higher level data were used when SES-level data were not directly available.

\subsection{General Description of the Messara Valley SES (Stage 1)}

The following brief description is based on a comprehensive storyline that compiled significant environmental, socio-economic, cultural, institutional and political data and events at the global, national, Crete and Messara Valley SES levels over the study period.

The Messara Valley, located in central-southern Crete, circa $50 \mathrm{~km}$ south of the city of Heraklion (Figure 1), constitutes the most important agricultural region of Crete. Formerly known as the breadbasket of Crete, it has retained its agricultural identity over the centuries. The focal Messara Valley SES has an area of 91,145.32 ha and has been defined on the basis of hydrological and land use criteria. It cuts across four municipalities and counts 74 settlements. Most of the area is cultivated. Parts of the hilly areas are covered by natural shrubby vegetation and are mostly used for grazing. Forests are practically absent. Pertinent higher spatial levels are the Heraklion prefecture, the Region of Crete and Greece.

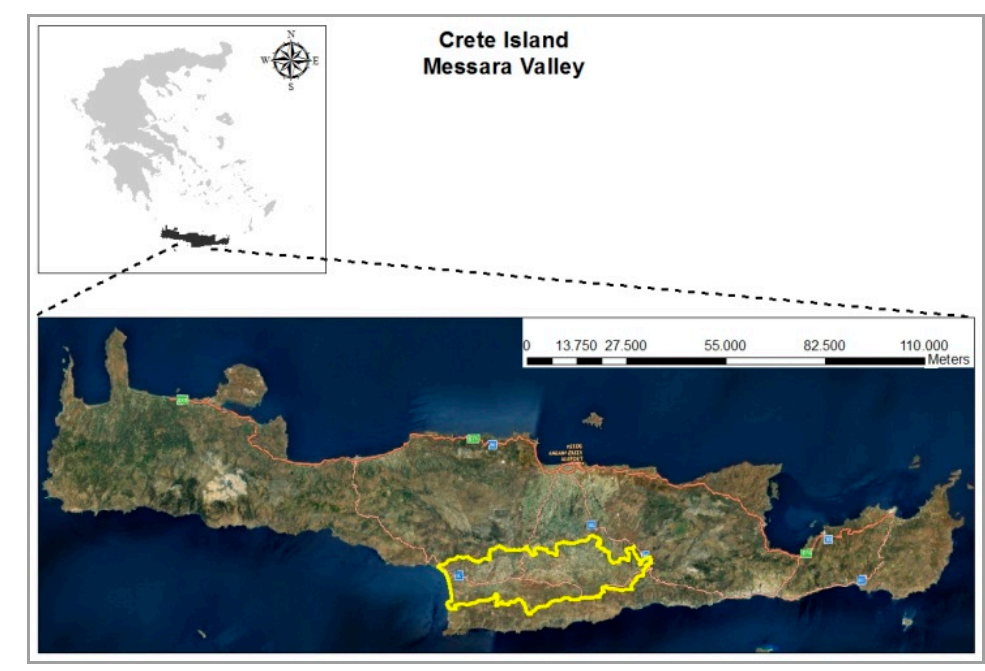

Figure 1. Location of the Messara valley.

The climate is sub-humid with mild moist winters and dry hot summers. The average altitude of the lower western part is less than $200 \mathrm{~m}$ while the altitude class $200-400 \mathrm{~m}$ dominates the eastern part, reaching up to $800 \mathrm{~m}$ a.s.l. Composite landforms, level land (dominating the southeastern part) and sloping land are encountered. The soils were formed on a variety of parent materials and have been greatly affected by topography and land management practices. Deep recent alluvial soils of various textures were formed in the lowland, deep, well or partially developed, soils of various textures and degrees of erosion were formed on Quaternary alluvial terraces and limestone patches, while partially developed soils were formed on residual parent materials, such as marl and flysch, on seriously eroded 
hilly areas. The water resources mainly comprise groundwater and two dams built in 1994 (currently being expanded) and 2005.

Agriculture and tourism along the northern coast were the pillars of the Cretan economy during the study period. The contribution of agriculture to income and employment has constantly been significantly higher than the national average (Tables 2 and 3). The most important products are olive oil, fruits and vegetables, especially those grown out of season due to the favorable climate. Occupation in agriculture has been declining since 1971; in 2001, it was one third of the 1971 figures at all levels (Table 2). While the national agricultural output fluctuated during the study period, agriculture in the Heraklion prefecture proved significantly more resistant, suffering a milder decline than the country average during the 1980s and exceeding the 1980 levels since then (Table 2). However, on the aggregate, its economic importance declined as elsewhere. Despite the paucity of local data, the Heraklion data satisfactorily reflect the situation of agriculture in Messara, as it is the most important agricultural area of the prefecture. The educational level of the Messara population has remained low, compared to the country average, despite the rapid spread of educational opportunities since the $1960 \mathrm{~s} .75 \%$ of the Messara population in 1991 and 64\% in 2001 had primary education at most.

Table 2. Occupation in agriculture, fisheries and forestry as \% of economically active population.

\begin{tabular}{ccccccc}
\hline Year & $\mathbf{1 9 6 1}$ & $\mathbf{1 9 7 1}$ & $\mathbf{1 9 8 1}$ & $\mathbf{1 9 9 1}$ & $\mathbf{2 0 0 1}$ & $\mathbf{2 0 1 1}$ \\
\hline Heraklion prefecture & 60.5 & 61.9 & 48.8 & 28.6 & 21.0 & 13.4 \\
Crete & 62.3 & 62.7 & 51.9 & 29.5 & 21.5 & 14.7 \\
Greece & 40.6 & 40.0 & 29.2 & 17.4 & 13.0 & 9.9 \\
\hline
\end{tabular}

Major political landmarks were the 1967-1974 dictatorship period, Greece's accession to the EEC in 1981 and two major administrative restructurings (1997 and 2010) that merged the more than 50 Messara communities and municipalities into nine in 1997 and four in 2010.

Table 3. Gross Value Added of agriculture of indicative years at constant (2005) prices.

\begin{tabular}{cccccc}
\hline Year & & $\mathbf{1 9 8 1}$ & $\mathbf{1 9 9 1}$ & $\mathbf{2 0 0 1}$ & $\mathbf{2 0 1 0}$ \\
\hline \multirow{2}{*}{ Greece } & million Euro & $15,763.36$ & 8104.519 & 8673.451 & 7416.522 \\
& \% of total & 15.88 & 6.95 & 5.99 & 4.31 \\
\hline \multirow{2}{*}{ Crete } & million Euro & 1522.348 & 765.455 & 714.883 & 663.680 \\
& \% of total & 27.95 & 12.15 & 9.27 & 8.00 \\
\hline \multirow{2}{*}{ Heraklion prefecture } & million Euro & 240.972 & 215.982 & 288.384 & 290.633 \\
& \% of total & 14.91 & 8.44 & 7.36 & 7.28 \\
\hline
\end{tabular}

Regarding the broader context, the Greek population was growing in the 1950-2000 period, despite massive migration abroad up to the early 1970's, and was relocating from rural areas to urban centers nationally and regionally. At the peak of rural outmigration (1951-1971), the population of Crete declined very modestly from 462,124 to 456,642 inhabitants and kept increasing since then, reaching 594,368 in 2001 and 623,065 in 2011. Urban population has almost tripled while rural population declined during this period, a pattern common throughout the northern Mediterranean (cf. [33]). The Messara SES population remained pretty stable, compared to other rural areas in Crete, counting 38,740 inhabitants in 1951, 40,795 in 1961, 38,626 in 1971, 42,476 in 1991, 41,007 in 2001 and 38,772 in 2011 (the decline found in 2011 was in accord with the overall trend of the greek population). However, the age distribution shows that the population is aging more quickly than the Greek and the Cretan average, although more slowly than the rural areas average in Crete.

\subsection{Evolution of the Dominant Human Responses in the Messara Valley SES (Stage 2)}

The principal response options during the study entire period were: traditional land management, agricultural intensification, outmigration, land use change and, post-2000 introduction of environment-friendly agricultural practices. 
In the beginning of the study period, circa 1950, rain-fed cereal cultivation was an attractive economic activity and major land use [32] that served local needs and the Cretan market. Limited grapevine, olive tree and vegetable cultivation and animal husbandry mostly served household needs. Fallow was widespread covering $18 \%$ of cultivated land (1961 agricultural census) and served as overwintering grounds for flocks from the neighboring Asteroussia Mountains SES [34]. Until circa 1960, available technology and economic means were extremely limited, the educational level was low, surplus labor was available and strong social and economic bonding networks dominated. Traditional farming was the only livelihood option and the dominant response option around which the Messara-level RA developed. Traditional land management practices, modes of economic organization and socio-cultural practices were territorialization processes that assembled and kept the RA components together.

From 1960 onwards, the dominant response started to change because a combination of changes at higher levels deterritorialized, modified and reassembled the RA components as the SES adapted to new conditions. Outmigration, due to job opportunities in urban centers, reduced the labor force and triggered the emergence of absentee land owners while bank credit availability made investments in mechanization possible. This combination produced a positive feedback that shifted the priorities of responses towards production intensification, starting with mechanization, around which the modified RA components reassembled.

Concurrently, growing cereal productivity in Greece reduced the importance of cereal cultivation in marginally suitable areas like Messara. According to calculations based on the available data of the official agricultural statistics the average cereal productivity in Greece rose from $990 \mathrm{~kg} / \mathrm{ha}$ in 1937 to $1655 \mathrm{~kg} / \mathrm{ha}$ in 1965. Average cereal productivity in Crete was only $835 \mathrm{~kg} / \mathrm{ha}$ in 1955, compared to $1240 \mathrm{~kg} /$ ha for Greece as a whole in the same year. Eventually, strong external competition rendered livelihoods based on cereal farming, whether traditional or mechanized, untenable in Messara. Traditional farming could continue by changing crops, which happened anyway. However, it became an undesirable response option when the means to adopt other, more profitable options became available.

The Messara farmers started switching to olive tree cultivation, initially employing traditional techniques. Olive groves were part of their farm strategy already; $95 \%$ of agricultural holdings included olive groves (1961 agricultural census), although regionally they were of secondary importance. Olive trees were favored because they were better suited than cereals locally, required less workforce, which was diminishing due to outmigration especially of the young, and favored absentee land ownership. The transition from cereals to olive tree cultivation did not occur abruptly; it lasted well into the 1980s because the time interval between planting olive trees, initiation of production and reaching full productive potential is significant. Thus, farmers can only gradually establish olive groves to avoid being left without income for several years.

The changes described so far were reflected also in the linkages of the Messara RA with higher spatial levels. The Messara households were connected to their members living in Heraklion or Athens and olive oil, unlike cereals, was increasingly traded outside Crete.

With respect to land degradation, soil erosion rates were often high during November and December when land was inadequately covered by the growing cereals, and during spring dry spells followed by showers. Although mature olive groves are less susceptible to erosion, during the first years after planting high erosion rates usually occur. The rate of change of the drivers underlying the emergence of the RAs in the Messara SES increased after 1970. Cereal productivity in mainland Greece accelerated further and new production technologies were introduced with the support of the Ministry of Agriculture, thus, sharpening competition with marginal areas. In the early 1970's, an outbreak of phylloxera (a new, unexpected RA component) destroyed most vineyards in Crete. Intensive tourism development, mainly along the northern coast, offered new job opportunities. Transportation infrastructure improved further; sea and air connections with Athens and European countries secured fast and safe transport of local products to distant markets. The attractiveness of 
agriculture both as livelihood option and productive activity diminished. These deterritorialization processes accelerated the changes in responses that had already started in the previous years. A period of intensive change between 1970 and the late 1980s ensued characterized by the emergence of an RA with blurred boundaries and fluid relationships among focal and external components.

Land use change from cereals to olive groves accelerated, generating a transient co-dominance of these two major land uses. A variety of crops was still grown for local consumption parallel to the dominant market crops. Land management intensified through the spread of mechanized cultivation and the application of fertilizers and other agro-chemicals, which were subsidized. The traditional sustainable contour shallow soil ploughing was replaced by unsustainable deep ploughing in various directions. The technological means for groundwater extraction became gradually available, increasing water availability to irrigate vegetables but also olive trees, although the latter remained rainfed mostly. The climatic and soil conditions, along with increased availability of financial resources and improved access to technology, also favored early or greenhouse vegetable cultivation, which commenced on the southwestern coastal strip in the 1970s. The agricultural statistics data reveal that the area dedicated to greenhouse vegetable production in the Heraklion prefecture rose from 143 ha in 1970 to 643 ha in 2000 and remained pretty constant since that time (653 ha in 2009). The vast majority of the greenhouses is found in the Messara area. All these improvements increased the productive potential of the area and led to higher production and income levels.

The changes in cultivation practices rendered tillage erosion a major degradation process in the sloping areas but erosion rates were lower than in the preceding period due to the spread of olive groves. The expansion of irrigation progressively resulted in over-exploitation of groundwater resources and brackish water intrusion in the lower aquifer of the Messara Valley since the 1980s. Greenhouse cultivation also contributed to increased soil and water resources use. Overall, the consequences of intensive agriculture started to be felt at the beginning of 1980's but the balance was still positive due to the benefits of the widespread land use change towards olive groves [32].

From the late 1980s onwards, a new deterritorialization force modified the socio-economic conditions: the accession of Greece to the European Union and the inflow of CAP and other EU subsidies to the Greek economy. Infrastructure improvements, e.g., expansion and modernization of the transportation network, medical and educational facilities, construction of small agricultural product processing factories, took place. The Messara population almost stabilized. After 1990, increasing foreign immigration, another deterritorialization force, offered cheap labor and kept many farms active, while local population aging continued. Tourism growth intensified causing further decline of the importance of the agricultural sector regionally, especially after 2000. The processes of change that were already underway since the 1970s continued; some of them peaked, modifying several of the RA components, adding new ones and changing their relationships. Eventually, a new RA emerged since the 1990s from the reassembling of the RA components.

Favored by the EU olive oil subsidies, olive groves eventually covered most of the Messara Valley SES after the mid-1990s. Orange and vine orchards also expanded in the lower part. Greenhouses expanded along the coast forming a very important local socio-economic module. In the coastal Tymbaki community 600 out of 1023 agricultural holdings included variously sized greenhouses that covered a total of 262 ha in 2009. The shift in CAP focus from production subsidies to rural development further fueled investment in greenhouses. Agricultural intensification reached a height with complete mechanization of land cultivation and expansion of irrigation networks in almost the whole Messara Valley, mostly drip irrigation, a new technology enabling effective utilisation of small-scale drillings (Table 4). Increased irrigation water availability led to constantly rising water demand (positive feedbacks). A dam was first built to meet this demand and a second followed as demand grew further. Fertilizer use kept increasing until circa 2000 when farmers realized their negative environmental and economic (increased cost) impacts and the trend reversed. Pesticide use kept increasing. Environmentally more benign practices were introduced after 2000. The efforts to 
promote integrated or organic farming practices have been successful, albeit covering a very limited part of Messara.

Table 4. Evolution of irrigated agricultural land in Messara.

\begin{tabular}{cccccc}
\hline Year & $\mathbf{1 9 6 1}$ & $\mathbf{1 9 7 1}$ & $\mathbf{1 9 9 1}$ & $\mathbf{2 0 0 1}$ & $\mathbf{2 0 0 9}$ \\
\hline Surface (ha) & 3034.6 & 5445.6 & $11,424.4$ & $16,415.67$ & $20,043.3$ \\
\% agricultural land & 6.29 & 11.30 & 23.70 & 34.06 & 46.5 \\
\hline
\end{tabular}

Agricultural intensification caused accelerated rates of soil erosion in the hilly areas. Aquifer water pollution became an important issue due to overuse of fertilizers and plant protection agrochemicals. Soil salinization became serious in the lower part of the RA. Despite the positive effects of the dominance of olive trees, the environmental and land conditions after the late 1980's were the worst of all over the study period [32].

Summarizing, the Messara Valley RAs emerged from processes related to the utilization of land resources for agricultural production. Despite changes, these resources continue to be available and no threshold has been crossed. The same applies to the human components of the SES; despite demographic and social changes, Messara remains a thriving area dominated by profitable agricultural activities. No economic, social or demographic threshold has been crossed that could indicate a SES transformation.

It is concluded that Messara retained its predominantly agricultural identity over the study period. The SES remained in the same, multi-dimensional basin of attraction moving within it and adapting to changes.

Three main phases (stages) of the Messara Valley SES were identified based on changes in the characteristics of critical biophysical and human components. Named after the dominant RA in each phase, they indicate the movement of the SES within the basin of attraction due to evolving local attractors; namely, from (a) the early "cereal modernization" attractor (1950 to 1970), a state period, (b) through the "olive transition" phase (1970 to late 1980s) to (c) the "olive subsidy" attractor, a state period (cf. [32]). The main features of each phase are summarized in Table 5.

Each phase is marked by a focal level RA possessing a characteristic biophysical and human profile associated with the local attractor. The first phase, the "1950 to 1970-cereal modernization" state period, is detailed below. Space limitations do not permit a complete presentation of Stage 3 for all three phases because the thrust of the present paper is to illustrate the application of the methodology outlined in Section 2. Repeating the same steps for the other two phases would add very little towards this purpose. The last section summarizes the socio-ecological dynamics of human responses in the Messara Valley SES over the study period.

\subsection{Analysis of SER and SEFRA in the 1950-1970 "Cereal Modernization Phase" (Stage 3)}

The 1950-1970 Messara-level RA that formed around the 'cereal modernization' attractor inherited several biophysical and human components from the pre-1950 traditional agriculture RA (soil, water, land cover, population, land management practices, agricultural produce, financial resources, social networks, culture). Some of them underwent changes over time while new ones were added especially from higher-level SESs; in particular, financial resources (cash) and farm technology. Territorialization processes, which assembled and held the components together, were mainly traditional farming and resource use practices, customary economic organization and local socio-cultural practices. Deterritorialization processes were post-1960 outmigration, technological change, tourism development and modernization of the Greek economy. The socio-ecological resilience (SER) and the socio-ecological fit of the RA of this phase are assessed following the procedure outlined in the previous section. 
Table 5. Main features of the three phases of the Messara Valley Socio-Ecological System.

\begin{tabular}{|c|c|c|}
\hline Phase & Macro-Conditions & Dominant Responses \\
\hline 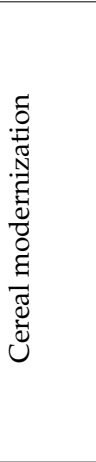 & $\begin{array}{l}\text { Economic stagnation and harsh } \\
\text { conditions until } 1960 \\
\text { Rapid economic growth afterwards; } \\
\text { credit became available making } \\
\text { investment in mechanization possible } \\
\text { Cereal production in Crete was } \\
\text { outcompeted by increased production } \\
\text { in the plains of central and northern } \\
\text { Greece after } 1960 .\end{array}$ & $\begin{array}{l}\text { Traditional agriculture } \\
\text { Labor-intensive cereal cultivation } \\
\text { dominated followed by olive trees and } \\
\text { vines. Very limited mechanisation } \\
\text { until the mid-1960's } \\
\text { Outmigration } \\
\text { Excessive, under-utilized, labor force } \\
\text { residing in rural areas due to lack of } \\
\text { alternatives, migrated to urban } \\
\text { centers or abroad. } \\
\text { Land use change \& intensification } \\
\text { From cereals to perennial crops, } \\
\text { mainly olives trees and vines }\end{array}$ \\
\hline 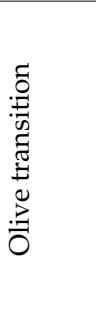 & $\begin{array}{l}1973 \text { world economic crisis ends the } \\
\text { rapid growth of the Greek economy } \\
\text { and the massive migration abroad. } \\
\text { 1967-1974 military dictatorship } \\
\text { 1981 EEC accession. Introduction of } \\
\text { CAP subsidies (1980s). } \\
\text { 1970s tourismdevelopment } \\
\text { accelerates in Crete. }\end{array}$ & $\begin{array}{l}\text { Land use change from cereals to } \\
\text { olives accelerated compared to the } \\
\text { past. } \\
\text { Agricultural intensification } \\
\text { (mechanisation, use of agrochemicals, } \\
\text { irrigation expansion) occurred rapidly. } \\
\text { Greenhouse cultivation commenced } \\
\text { in the climatically suitable southwest } \\
\text { coastal area (1980s). }\end{array}$ \\
\hline 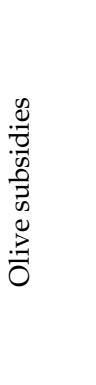 & $\begin{array}{l}\text { Agricultural subsidies and rural } \\
\text { development programs were } \\
\text { important external socio-economic } \\
\text { factors of change. } \\
\text { Food processing and plastics } \\
\text { industries continue to grow in Greece } \\
\text { despite de-industrialization trends in } \\
\text { other sectors. } \\
\text { Tourism became a major industry in } \\
\text { Greece with repercussions in the } \\
\text { construction sector. }\end{array}$ & $\begin{array}{l}\text { Irrigation expansion favored by dam } \\
\text { construction and new technology that } \\
\text { enabled effective utilisation of } \\
\text { small-scale drillings. } \\
\text { Shift in CAP focus from production } \\
\text { subsidies to rural development fueled } \\
\text { investment in greenhouses. } \\
\text { Introduction of integrated and } \\
\text { organic farming. }\end{array}$ \\
\hline
\end{tabular}

\subsubsection{Step 1: Assessment ofLower Level Properties (LLPs)}

The following LLPs were assessed separately for the biophysical, economic, and social components of the RA: potential, robustness, redundancy, diversity, modularity, openness and connectedness (see Table 1). The bulk of the analysed data and information was collected in the course of the research project LEDDRA. Quantitative and qualitative assessment techniques were used depending on the component and LLP. For the biophysical components, the assessment considered the availability of adequate resources for the dominant land use, agriculture, conditions that would threaten critical environmental functions and the spatial distribution of them, as well as of the different land use/land cover types (for details, see [32]. For the economic and social components, qualitative assessments, based on informed reasoning and expert judgment, were obtained on the basis of the statistical analysis of secondary and interview data regarding population size and age-sex composition, financial resources, sectoral composition, agricultural and other technology employed, human resources (occupational composition, education and skills),social capital, social facilities (schools, health centers, etc.), cultural traits, landesque capital (dams, irrigation networks, farm structures), physical infrastructure (road and communication networks), and national and local formal and informal institutions.

The potential of land resources was high during this period. Fertile soil and irrigation water were available. However, climate was marginal for the dominant crop (cereals). The land resources were not threatened by a conceivable threat and the technology used was available locally. Particularly strong cultural values dominated locally. Overall, the Messara Valley RA was robust in the first phase. Owing to limited financial and technological means, the use of land resources, especially water, was far from 
reaching its limits. Land management was based on abundantly available human labor. Informal human capital, i.e., LEK-driven production practices, was relatively high, especially during the 1950s. Strong social bonds secured high social capital and redundancy as local social networks could provide extra resources when required.

The RA was characterized by low openness as it was strongly connected and relatively open to its immediate surroundings but not to national and international levels because of limited economic and social linkages. An important part of the agricultural products was sold outside the area but mostly within Crete. Links to stockbreeders of the neighboring Asteroussia SES provided extra connections reinforcing the significant role of Messara in its wider surroundings [35]. Outmigration and olive oil trade gradually led to the formation of social and economic connections with urban centers, primarily Heraklion and Athens.

The diversity of the RA was low, mainly because of the dominance of a limited number of arable annual crops produced, complemented by olives and vines. The local society had a modular organization along kin lines but, with respect to land use and management, the overall importance of this modularity was limited because all different groups shared the same practices.

\subsubsection{Step 2: Assessment of System Level Properties (RAT).}

The assessment of R, A, and T involved two stages [8]. First, independent assessments of R, $\mathrm{A}$ and $\mathrm{T}$ were obtained by examining the geometry of the basin of attraction (latitude, resistance, precariousness and panarchy) and the place of the actual RA in it to estimate Resilience (R) and Adaptability (A). Transformability was not considered because it was not relevant in this period.

Second, the place- and time-specific combinations of LLPs associated with critical and other biophysical and human RA components that are considered to shape/explain the historical/observed 'values' of R and A of the RA were identified. A Resilience Assessment Matrix (RAM) and an Adaptability Assessment Matrix (AAM) were set up to provide a synoptic picture of the values of the LLPs for the RA under study. Provisional, multidimensional measures of $R$ and A were, thus, obtained reflecting the distributive and composite nature of the RA. This assessment revealed the capacities of the critical RA components to maintain the ability of a SES to develop sustainably under a given style of structuration of the RA.

A 5-point (very low to very high) assessment scale was used to 'normalize/standardize' the heterogeneous estimates of the LLPs in the RAM and AAM and facilitate the discussion of the comparative assessment of the contribution of the properties of each RA component to the Resilience and Adaptability of the RA studied.

Following this procedure, the independent values of $\mathrm{R}$ and $\mathrm{A}$ resulted from evaluating the range of values and the distribution of the biophysical, economic and social components of the Messara RA based on the data collected usually using scientific judgment (panel of experts and personal judgment) in the particular geographical context of the study area. RAM and AAM were set up using the assessments of LLPs from Step 1. Their normalized/standardized versions appear in Tables 6 and 7. These were produced by means of expert judgment (the authors and other researchers participating in LEDDRA) who evaluated the LLPs in the context of the quantitative and interview data collected from the Messara SES. It is noted that some cells of the matrices appear blank or marked as ' $n / a$ ' (not applicable). Blank cells appear where assessment of an LLP was not possible due to lack of, at least elementary, data; e.g., the robustness of physical infrastructure (Table 6) or the modularity of financial resources, landesque capital, population, human resources and culture (Table 7). The ' $\mathrm{n} / \mathrm{a}$ ' mark denotes that the LLP for the component concerned did not make sense in general because the component is variable and rather unpredictable; e.g., the robustness, redundancy and connectedness/openness of climate (Table 6) or the openness of the landesque capital (Table 7). 
Table 6. Resilience Assessment Matrix (RAM) of the "Cereal modernization phase, 1950-1970".

\begin{tabular}{|c|c|c|c|c|}
\hline & \multicolumn{4}{|c|}{ Lower Level Properties (LLPs) and Associated Characteristics of the Basin of Attraction } \\
\hline & $\begin{array}{l}\text { Potential Available } \\
\text { for Change } \\
\text { (Latitude) }\end{array}$ & $\begin{array}{l}\text { Robustness } \\
\text { (Resistance) }\end{array}$ & $\begin{array}{c}\text { Redundancy } \\
\text { (Precariousness) }\end{array}$ & $\begin{array}{c}\text { Connectedness/Openness } \\
\text { (Panarchy) }\end{array}$ \\
\hline \multicolumn{5}{|c|}{ Biophysical system } \\
\hline Soil & $* * * *$ & $* * * *$ & $* * * *$ & $\mathrm{n} / \mathrm{a}$ \\
\hline Vegetation & $* *$ & $* *$ & $* *$ & $\mathrm{n} / \mathrm{a}$ \\
\hline Water & $* * *$ & $* * *$ & $* * *$ & $\mathrm{n} / \mathrm{a}$ \\
\hline Climate & $* * *$ & $\mathrm{n} / \mathrm{a}$ & $\mathrm{n} / \mathrm{a}$ & $\mathrm{n} / \mathrm{a}$ \\
\hline \multicolumn{5}{|c|}{ Economic system } \\
\hline Economic structure & ** & ** & $* * *$ & $* * * *$ \\
\hline Financial resources & * & $\mathrm{n} / \mathrm{a}$ & * & * \\
\hline Landesque capital & $* *$ & $* * *$ & $\mathrm{n} / \mathrm{a}$ & $\mathrm{n} / \mathrm{a}$ \\
\hline Physical infrastructure & $*$ & & $\mathrm{n} / \mathrm{a}$ & $\mathrm{n} / \mathrm{a}$ \\
\hline Technology & $* *$ & $* *$ & $\mathrm{n} / \mathrm{a}$ & $*$ \\
\hline Plant, animal capital & $* *$ & $* *$ & $\mathrm{n} / \mathrm{a}$ & $\mathrm{n} / \mathrm{a}$ \\
\hline \multicolumn{5}{|c|}{ Social system } \\
\hline Population & $* * * *$ & $* * * *$ & $* * * *$ & $* * * *$ \\
\hline Human resources & $* * *$ & $\mathrm{n} / \mathrm{a}$ & $* * *$ & $\mathrm{n} / \mathrm{a}$ \\
\hline Culture & $* * * *$ & $* * * *$ & $\mathrm{n} / \mathrm{a}$ & $* * *$ \\
\hline $\begin{array}{l}\text { Social structure and } \\
\text { social capital }\end{array}$ & $* * *$ & $* * * *$ & * & $* * * *$ \\
\hline Institutions & $* * *$ & $* * * *$ & * & $* * * *$ \\
\hline
\end{tabular}

Contribution of LLPs to shaping the historical/observed value of Resilience. ${ }^{* * * * *}$ : Very strong contribution (non encountered), ${ }^{* * * *}$ : Strong contribution, ${ }^{* * *}$ : Moderate contribution, ${ }^{* *}$ : Low, ${ }^{*}$ : Very low contribution, $\mathrm{n} / \mathrm{a}$ : not applicable, blank cells: not assessed.

Table 7. Adaptability Assessment Matrix (AAM) of the "Cereal modernization phase, 1950-1970".

\begin{tabular}{|c|c|c|c|c|c|}
\hline & \multicolumn{5}{|c|}{ Lower Level Properties (LLPs) and Associated Characteristics of the Basin of Attraction } \\
\hline & $\begin{array}{c}\text { Potential } \\
\text { Available for } \\
\text { Change } \\
\text { (Latitude) }\end{array}$ & $\begin{array}{c}\text { Diversity } \\
\text { (Latitude, } \\
\text { Resistance) }\end{array}$ & $\begin{array}{l}\text { Connectedness } \\
\text { (Precariousness, } \\
\text { Panarchy) }\end{array}$ & $\begin{array}{c}\text { Modularity } \\
\text { (Latitude, } \\
\text { Resistance) }\end{array}$ & $\begin{array}{l}\text { Openness } \\
\text { (Latitude, } \\
\text { Resistance, } \\
\text { Panarchy) }\end{array}$ \\
\hline \multicolumn{6}{|c|}{ Economic system } \\
\hline Economic structure & $* *$ & ** & *** & $* *$ & ** \\
\hline Financial resources & * & ** & * & & * \\
\hline Landesque capital & $* *$ & $* *$ & & & $\mathrm{n} / \mathrm{a}$ \\
\hline Physical infrastructure & * & * & * & ** & \\
\hline Technology & ** & * & * & & ** \\
\hline Plant, animal capital & $* *$ & & & $* *$ & \\
\hline \multicolumn{6}{|c|}{ Social system } \\
\hline Population & $* * * *$ & $* *$ & $* * * *$ & & $* * * *$ \\
\hline Human resources & $* * *$ & $* *$ & & & \\
\hline Culture & $* * * *$ & * & $* * * *$ & & $* *$ \\
\hline $\begin{array}{l}\text { Social structure and } \\
\text { social capital }\end{array}$ & $* * *$ & $* *$ & $* * * *$ & $* * *$ & $* * * *$ \\
\hline Institutions & $* * *$ & * & $* * * *$ & * & $* * * *$ \\
\hline
\end{tabular}

Contribution of LLPs to shaping the historical/observed value of Adaptability. ${ }^{* * * * *}$ : Very strong contribution (non encountered), ${ }^{* * * *}$ : Strong contribution, ${ }^{* * *}$ : Moderate contribution, ${ }^{* *}$ : Low, ${ }^{*}$ : Very low contribution, n/a: not applicable, blank cells: not assessed.

The independent assessment of Resilience, along the environmental, economic and social dimensions, offered a mixed picture. The latitude of the basin of attraction in the 1950-1970 phase can be considered large due to the availability of abundant natural resources, which made the area suitable for growing a wide range of crops, and surplus labor, although it gradually diminished due to outmigration. However, economic resources, although decent for a Greek rural area at that time, were in short supply, thus, limiting the overall potential available for change. This potential did not 
face any significant challenge. Human pressures on land resources with the means available were within the resource limits, privileged agricultural areas, like Messara, generally retained significant segments of their productive population despite outmigration and the limited economic means were constantly recycled in the local economy. Therefore, the RA appeared highly robust. Biophysical and social potential were largely redundant providing the opportunity to recover or break new ground if needed, despite the limited economic potential. Because climate was only marginally suitable for the dominant land use, cereal cultivation, the RA was positioned close to the brink of the basin that rendered it relatively precarious. The limited modularity would not have insulated compartments of the RA effectively from a harvest failure. Originally, the connection to the Asteroussia SES, through transhumance practices, and the broader Heraklion area, through trading of surplus cereal production, acted as a stabilizing force. At the farm level, routine practices reinforced the dominant production model. The combined examination of the LLPs suggest that Resilience of the RA should be considered high during that phase.

The historical outcome confirms this finding, since the identity of the area as a productive farming region was preserved. High potential available in the form of land resources proved to be the most important aspect, enabling land use change and intensification.

The resistance of the basin is difficult to assess as no major perturbations occurred in the 1950-1970 period. Large external shocks prior to 1950 (the SES was essentially similar to this period), namely the 1932 national bankruptcy and WW II, have not produced significant changes. A severe drought that would destabilize the system did not occur. The area was strongly connected and relatively open to its immediate surroundings, but not to the national and international environment. The latter characteristic stabilized the existing RA since this cereal producing area was particularly well-placed in the regional system at times of cereal deficiency. Links to Asteroussia SES stockbreeders provided extra connections reinforcing the significant role of Messara in the wider Heraklion area.

Land use intensification and land use change towards olive groves, a more drought resistant crop, widened and deepened the basin of attraction moving the RA away from the brink of the basin. Thus, the independent assessment of the Messara RA along the economic and social dimensions, based on historical evidence, indicates that it adapted satisfactorily to the changes that occurred in this phase. The inhabitants successfully responded to external stimuli by altering the way of interacting with land resources. Change was not resisted; however, because it was incremental and the local environmental and social potential was adequate to manage the magnitude and type of this change, the identity and resources of the area were largely preserved.

Turning to Adaptability, the diversity of all components of economic and social capital was moderate. Connectedness and openness were well developed with the immediate surroundings but not with the higher levels. Modularity in economic terms was very limited because, as mentioned before, the extant modules exhibited similar behavior that detracted from the beneficial effects of modularity on Adaptability. In sum, the Adaptability of the Messara RA, based on the combinations of the LLPs considered, was low in the first phase which is somehow at odds with the fact that it did adapt successfully.

Transformability is not relevant in this phase because the SES did not undergo a transformation nor did it face a major perturbation. It can be argued that an intentional transformation to a non-farming identity would have not been possible. Social capital was hardly suited for anything but farming and economic resources were largely lacking or very limited throughout the phase. Social and economic potential available for a transformation was, therefore, in short supply. It is noted that the economy of both Greece and Crete were growing rapidly between 1960 and1973. The focus of national policies was not on agriculture (that might had affected Messara) but on tourism that facilitated its development on the island, boosting employment and income, and dramatically affected its transformation in the following phase. 


\subsubsection{Step 3: Assessment of SER}

SER was assessed by synthesizing the provisional multi-dimensional assessments of $\mathrm{R}$ and $\mathrm{A}$ (as shown in RAM and AAM) to back an independent assessment of the observed/historical SER of the RA [8]. The independent assessment of SER resulted from evaluating the features of the basin of attraction of the Messara RA in the 1950-1970 phasebased on the historical biophysical and socio-economic data collected and using scientific judgment (panel of experts and personal judgment) in the particular geographical context of the study area.

A SER Assessment Matrix (SERAM), which resulted from merging RAM and AAM, produced a provisional, multidimensional measure of SER that provided a synoptic picture of the place- and time-specific combinations of LLPs of critical biophysical, social and economic components which 'explained' the historic/observed value of SER in the period. As it was the case with RAM and AAM, a 5-point assessment scale was used to 'normalize/standardize' the heterogeneous estimates of the LLPs in SERAM (Table 8) and, thus, facilitate the discussion of the comparative contribution of the properties of each RA component to the SER of the RA studied.

Table 8. Socioecological Resilience Assessment Matrix (SERAM) of the "Cereal modernization phase, 1950-1970".

\begin{tabular}{|c|c|c|c|c|c|c|c|}
\hline & \multicolumn{7}{|c|}{ Lower Level Properties (LLPs) and Associated Characteristics of the Basin of Attraction } \\
\hline & $\begin{array}{l}\text { Potential } \\
\text { Available for } \\
\text { Change } \\
\text { (Latitude) }\end{array}$ & $\begin{array}{l}\text { Robustness } \\
\text { (Resistance) }\end{array}$ & $\begin{array}{c}\text { Redundancy } \\
\text { (Precarious-Ness) }\end{array}$ & $\begin{array}{l}\text { Diversity } \\
\text { (Latitude, } \\
\text { Resistance) }\end{array}$ & $\begin{array}{l}\text { Connected-Ness } \\
\text { (Precarious-Ness, } \\
\text { Panarchy) }\end{array}$ & $\begin{array}{l}\text { Modularity } \\
\text { (Latitude, } \\
\text { Resistance) }\end{array}$ & $\begin{array}{l}\text { Openness } \\
\text { (Latitude, } \\
\text { Resistance, } \\
\text { Panarchy) }\end{array}$ \\
\hline \multicolumn{8}{|c|}{ Biophysical system } \\
\hline Soil & $* * *$ & $* * *$ & $* * *$ & & $\mathrm{n} / \mathrm{a}$ & $\mathrm{n} / \mathrm{a}$ & $\mathrm{n} / \mathrm{a}$ \\
\hline Vegetation & $* * *$ & $* *$ & $* *$ & $* *$ & $\mathrm{n} / \mathrm{a}$ & $\mathrm{n} / \mathrm{a}$ & $\mathrm{n} / \mathrm{a}$ \\
\hline Water & $* * *$ & $* * *$ & $* * *$ & $\mathrm{n} / \mathrm{a}$ & $\mathrm{n} / \mathrm{a}$ & $\mathrm{n} / \mathrm{a}$ & $\mathrm{n} / \mathrm{a}$ \\
\hline Climate & $* *$ & $\mathrm{n} / \mathrm{a}$ & $* *$ & & $\mathrm{n} / \mathrm{a}$ & $\mathrm{n} / \mathrm{a}$ & $\mathrm{n} / \mathrm{a}$ \\
\hline \multicolumn{8}{|c|}{ Economic system } \\
\hline Economic structure & $* *$ & $* *$ & $* *$ & $* *$ & $* * * *$ & * & ** \\
\hline Financial resources & * & $\mathrm{n} / \mathrm{a}$ & * & $*$ & $*$ & & * \\
\hline Landesquecapital & $* *$ & $* * *$ & $\mathrm{n} / \mathrm{a}$ & $* *$ & $\mathrm{n} / \mathrm{a}$ & & $\mathrm{n} / \mathrm{a}$ \\
\hline $\begin{array}{c}\text { Physical } \\
\text { infrastructure }\end{array}$ & * & & $\mathrm{n} / \mathrm{a}$ & * & $*$ & $* *$ & $\mathrm{n} / \mathrm{a}$ \\
\hline Technology & $* *$ & $* *$ & $\mathrm{n} / \mathrm{a}$ & * & * & & * \\
\hline Plant, animal capital & $* *$ & $\mathrm{n} / \mathrm{a}$ & $\mathrm{n} / \mathrm{a}$ & & $\mathrm{n} / \mathrm{a}$ & $* *$ & $\mathrm{n} / \mathrm{a}$ \\
\hline \multicolumn{8}{|c|}{ Social system } \\
\hline Population & $* * * *$ & $* * * *$ & $* * *$ & $* *$ & $* * * *$ & & $* * *$ \\
\hline Human resources & $* * * *$ & $\mathrm{n} / \mathrm{a}$ & $* * *$ & * & $\mathrm{n} / \mathrm{a}$ & & $\mathrm{n} / \mathrm{a}$ \\
\hline Culture & $* * * *$ & $\mathrm{n} / \mathrm{a}$ & $\mathrm{n} / \mathrm{a}$ & * & $* * * *$ & & $*$ \\
\hline $\begin{array}{l}\text { Socialstructure and } \\
\text { social capital }\end{array}$ & $* * * *$ & $* * * *$ & * & ** & $* * * *$ & $* * *$ & $* *$ \\
\hline Institutions & $* * *$ & $* * * *$ & * & * & $* * * *$ & * & $* * *$ \\
\hline
\end{tabular}

The human responses of the period fed back and modified the morphology of the basin of attraction and the place of the actual RA within it. Despite the observed, very modest however, reduction of the potential of natural resources, soil and water were largely preserved through traditional agriculture while rising financial resources slowly enabled intensification which, along with land use change, enhanced the economic conditions of the area, increasing the latitude of the basin through positive feedbacks. The resistance of the SES was enhanced because the change from cereals to olive trees improved its robustness. Olive trees are less easy, socially unacceptable and slow to uproot. The enhanced drought resistance, compared to cereals, reduced the precariousness of the SES, along with the improved modularity that resulted from the two distinct cultivations, cereals and olive trees. From the point of view of local farmers, SER increased during this period despite the slight 
reduction of the biophysical potential, since its effects were more than counterbalanced by increases in the economic potential. The overall moderate to high SER, an indication that the SES was developing sustainably, is accounted by the fact that under the style of structuration of the Messara RA of this phase the capacities of the critical SES components were not exceeded.

The most crucial LLP explaining its high values is the potential of land resources that enabled locals to successfully adopt a new cultivation which secured the preservation of local crop production. This adoption also occurred within a context that did not challenge the resilience of the SES. The first half of the phase was socially and economically very harsh but stable and no pressures arose different from those the area was long-accustomed to. The second half was characterized by the unprecedented and unique economic growth of Greece.

\subsubsection{Step 4: Assessment of SEFRA}

The multidimensional assessment of SER obtained for the 1950-1970 phase was evaluated using the LLPs as evaluation criteria to gauge the degree to which the RA functioned satisfactorily; i.e., how human responses promoted the preservation of SER in this phase.More specifically, the entries of SERAM were compared against cutoff values of the corresponding LLPs for the respective RA components. For the biophysical LLPs, cutoff values based on the scientific literature were used to determine whether the value of an LLP for a SES component (e.g., potential of soil, water resources, etc.) was satisfactory or not for adequately preserving ecological and land use functions under the particular environmental conditions. For the economic and social LLPs, expert/informed judgment, based on the secondary and interview data collected, determined ranges of cut-off values (for, e.g., financial resources, technology, population, human resources, culture, etc.). These were used to evaluate whether the values of the LLPs for the human components contributed to the preservation of the socio-economic and cultural functions under the prevailing socio-economic and other conditions of the period.

A provisional, contextual and contingent, composite and distributive assessment of SEFRA was obtained by combining these evaluation scores, reflecting the synthesis of the biophysical, social and economic fit of the RA. As before, a 5-point scale was used to 'normalize/standardize' the heterogeneous evaluations of the LLPs in SEFRAM (Table 9) to support the discussion of the comparative role of the properties of each RA component to the socio-ecological fit (SEFRA) of the RA. Note that more than one SEFRA assessments are possible for different assessments of SERAM [8].

Combining all scores using informed (scientific) reasoning and expert judgment, it was concluded that the socio-ecological fit of the Messara focal RA in the 1950-70 phase was satisfactory, in the sense outlined in Section 2: it promoted the preservation of SER within the period under consideration. This assessment is in agreement with the moderate to high assessment of SER mentioned before. The main reasoning supporting this finding is summarized below.

At the beginning of this period, circa 1950, traditional farming was the only available livelihood option and matched well the technology and economic means available as well as the priority given to securing the long-term productive capacity of the land for future generations of the family. Cereals were in short supply in Crete as well as in Greece and the obvious response was to grow them and sell the surplus for cash, an option worth utilizing even in places that were not ideal for cereal cultivation, like Messara. The modernization of agriculture and of the Greek economy in the 1960s lessened the suitability of this response for the Messara SES as it undermined both the scope of growing cereals and of traditional land management in general. At the same time, outmigration was enabled leading to non-agricultural livelihoods. 
Table 9. Socioecological Fit of the Response Assemblage Assessment Matrix (SEFRAM) of the “Cereal modernization phase, 1950-1970".

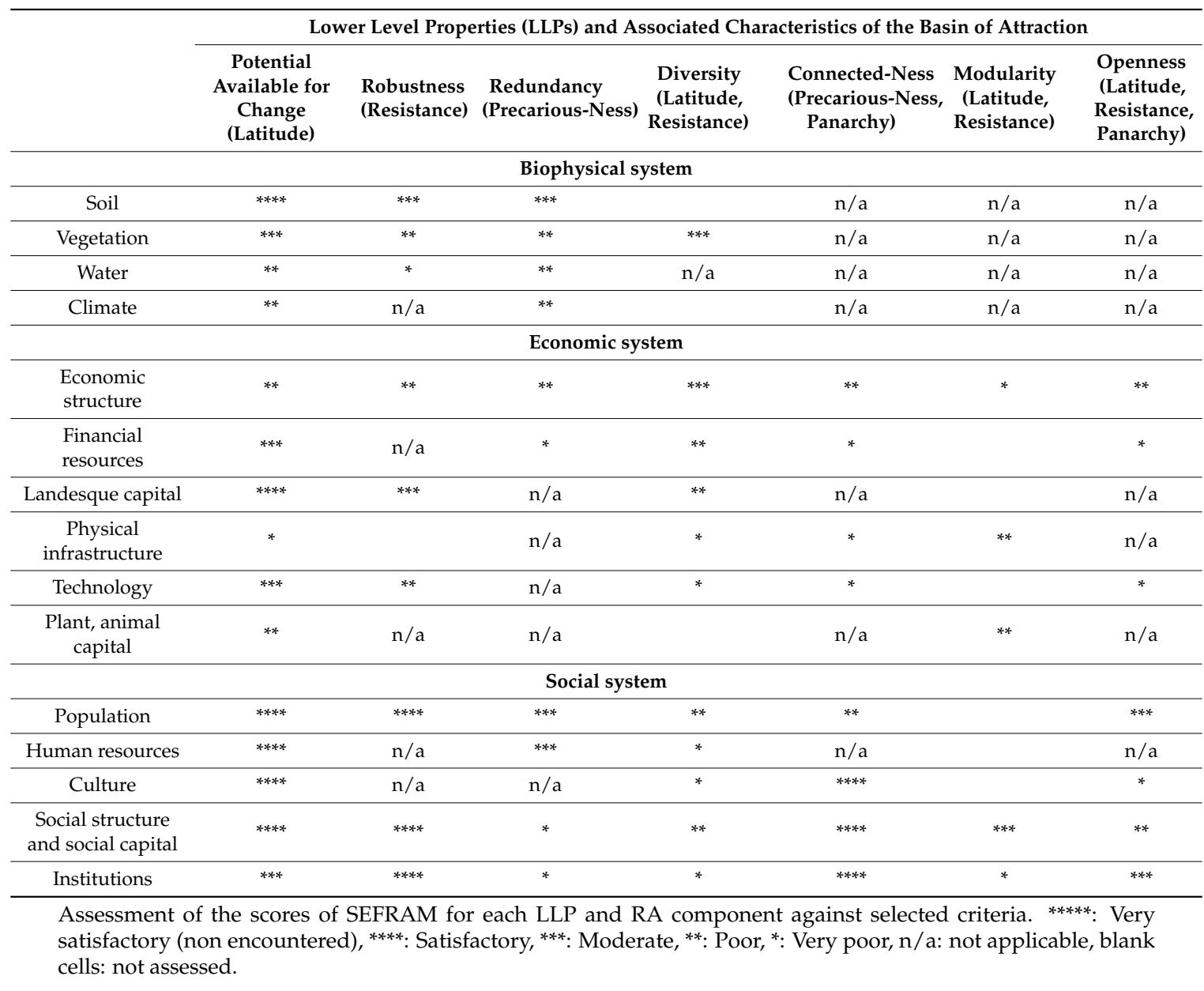

Even though traditional farming is usually considered a sustainable practice, soil erosion affected approximately $15 \%$ and land desertification risk almost $75 \%$ of the total area during this period [32]. The RA did face limited land degradation problems, both during cereal cultivation and in the early years of olive grove establishment, due to the poor technological means and the relatively careful land management. Although the RA was partially unfit land degradation-wise, the positive social and economic outcomes led to a positive change of SER and an increase in the capacities of the RA components, as outlined before. By the end of this phase, all kinds of major response options (outmigration, land use change, production intensification) were tried and found possible and suitable. The SES, thus, entered a phase of rapid change exemplified by the disassembling of the "1950-1970 cereal modernization" RA. The increase in SER points to a suite of suitable responses. During this new phase, olive tree cultivation, a previously second-order response, rapidly gained importance and played a central role in re-assembling the components and the emergence of a different RA.Stage 4 (Design of ORAs) is omitted because it is not relevant for the 1950-1970 phase. The analysis of the other two periods proceeded following the same procedure.

\subsection{The Socio-Ecological Dynamics of Human Responses in the Land Degradation-Affected Messara Valley SES, 1950-2010}

Based on the analysis of the three phases, a concise overview of the socio-ecological dynamics of human responses in the land degradation-affected Messara Valley SES over the 1950-2010 study period is offered to demonstrate that their emergence and evolution was driven by changes in their 
effectiveness to serve human purposes at particular time periods, i.e., in the socio-ecological fit of the emergent RAs, that reflect changes in the socio-ecological resilience of the respective RAs.

The "1950-1970 cereal modernization" RA emerged as an adaptation of the Messara SES to changing socio-economic conditions by means of three main response options-outmigration, land use change, production intensification-that the local population tried and found fit. In the absence of external developments that would put this fit into question, positive feedbacks accelerated change. A new RA component was added during this period, namely, greenhouse cultivation (a response option), made possible by a combination of the relevant technology (originally introduced in eastern Crete in the late 1960 's), capital availability to establish the first installations and improvement in transport infrastructure and means that enabled trading fresh vegetables outside Crete.

The adaptation processes accelerated the changes in LLPs that were already under way. The increased availability of economic resources, including technology, outweighed the reduction in available labor force. Olive groves, which were gaining importance at the expense of cereals, were less susceptible to change, since they represented a long-term investment. In environmental terms, they are more resistant against drought spells and, after the initial establishment phase, less prone to soil erosion. The land cover and land management changes led to a breakdown of the connections with the neighboring Asteroussia SES, as fallow lands suitable for overwintering sheep flocks progressively became unavailable, and the development of closer economic linkages with Athens and the (then) E.E.C. later. These deterritorialization processes led from the 1950-1970 RA that was linked to its surroundings to the emergence of the transitory 1970-late 1980s RA that opened up to higher spatial levels at the expense of within-Crete, regional linkages. Land use diversity increased due to the co-dominance of cereals and olive groves and the addition of greenhouses. Similarly, modularity increased.

On the basis of the historical outcome of the 1970-late 1980's transition phase, the socio-ecological resilience of the respective RA can be considered high. Resilience was high and the adaptation process that had commenced in the previous phase triggered positive feedbacks. Its pace accelerated for most of the transition phase, with a switch from cereals to olive trees and, to a limited extent, to greenhouses, as well as with investment in agricultural and irrigation equipment. The 1970-late 1980's RA did not face challenges that could overwhelm its capacity to adapt.

With respect to land degradation, this RA rated better than the previous and the next ones [32] due to the combination of olive groves expansion with moderately intensive management. Several RA components, such as income, improved also in this phase. Consequently, SEFRA should be considered high. It is reminded, however, that this phase is a transition period during which the influence of higher spatial levels was increasingly being strongly felt in the area (panarchy) and significantly shaped its trajectory. In a sense, the seeds of the issues that emerged in the next phase can be traced to the management of socio-ecological affairs in this transition phase.

The same response options carried over to the next, the olive subsidy phase. The 1981 accession of Greece to the EU had set in motion deterritorialization processes that re-assembled the RA components into the olive subsidy RA that emerged after 1990. New components (production and investment subsidies) were added and existing components were modified (olive groves further expansion and management intensification and greenhouse expansion mostly). These processes initially enhanced significantly the available economic potential. The influx of Eastern European immigrants in the 1990 's increased redundancy with respect to available labor and balanced the aging local workforce. The spread of the olive groves irrigation practice rendered irrigation water a limiting factor in some areas. Irrational soil management also caused widespread erosion problems. Connectedness and openness with the national and international levels increased and decreased further with the local and regional levels. Consequently, the panarchy within which the RA was embedded led to increased openness, diffusion of new ideas and increased vulnerability to external developments. The spread of greenhouse cultivations significantly enhanced the modularity of the RA, although its significance is restricted to the coastal strip. Land use diversity diminished since olive groves became a monoculture. In economic terms, however, diversity increased as non-agricultural occupation was spreading in 
the area. Robustness became very high due to the densely connected and resistant social networks formed around the distribution of olive oil and olive tree-related subsidies. These networks became locked in their effort to retain their original structure, which was constantly challenged, however, by changing subsidy allocation rules. Land resources started to become limiting for the first time, although problems remained localised. Conflicts between agricultural and domestic/tourism use of freshwater occasionally arose as irrigation water is indispensable for greenhouse cultivations and for intensively-managed irrigated olive groves. The question whether large-scale non-irrigated cultivation would be profitable enough is crucial. Profitability of olive oil production was constantly declining until 2010 due to generally falling (though fluctuating) olive oil prices and constantly increasing input prices, two processes initiated by external developments.

The identity of the area as a productive farming region was preserved; the increasing significance of non-agricultural activities enriched but did not challenge its agricultural identity. The socio-ecological resilience of the olive subsidy RA can be considered medium because of olive oil declining profitability, water scarcity risk and increasing vulnerability of the RA owing to dependence on factors beyond the ability of local actors to influence. The success of greenhouse farming that could outweigh this vulnerability gradually became precarious due to resource limitations. Overall, although living conditions had initially improved significantly, SER was diminishing. Land degradation aggravated compared to the previous phase [32]. The deterioration of natural resources points to reduced fit. Soil erosion increased due to the sprawl of intensively-cultivated olive groves in natural areas, water shortages occurred due to aquifer over-exploitation and water pollution risk increased due to overuse of fertilizers. The precariousness of the RA due to the emerging environmental issues as well as the diminishing returns from olive tree cultivation suggest a general reduction of SEFRA. Whether initial efforts to adapt through potentially more environmentally and economically efficient practices suffice, remains to be seen. Summing up, the trajectory of the SES was marked by an RA initially formed around traditional agriculture in the 1950's, a transitional RA forming around crop change and agricultural specialization and intensification, to the last RA forming around subsidies. The most consistent change in LLPs during the study period was the breaking up of local connections of Messara in favor of distant connections. Similar processes occurred in all productive agricultural areas of Europe since the 1950s driven by forces external to the SESs and beyond the ability of locals to influence [36].

The changes in external conditions triggered changes in LLPs that altered the fit of responses. In some cases, loss of fit of a specific response option and adoption of another indicated its inability to continue. For example, traditional agriculture became unattractive because the Messara farmers could not make a living from cereal cultivation anymore. As soon as other options became available, agricultural intensification and outmigration ensued. Up to 2010, resource limitations did not induce any adaptation; environmental gains and losses were by-products of response options evolving without explicit consideration of LD or limitations imposed by LD. Only recently resource shortages and environmental problems obtained importance and are explicitly considered in local decision making.

\section{Conclusions}

This paper demonstrated the application of an integrated methodology developed to assess the effectiveness of human responses to combat environmental degradation in the case of the land degradation-affected Messara Valley (Crete, Greece) SES. The methodology synthesizes the relational and non-reductionist assemblage ontology with diagnostic SES analysis and Resilience Thinking to approach the situated assessment of the socio-ecological fit of human responses-in-context conceptualized as responses assemblages [8]. The methodology has two distinctive features; first, the objects of analysis are the individual RAs emerging over a study period in a focal SES and not "the SES as a whole"; SEFRA, the measure of effectiveness, is always tied to a particular RA and it does not have meaning outside of it. Second, emphasis is placed not on individual SES characteristics but on RA properties that reflect place- and time-specific relationships among SES components, which 
are assembled into RAs, and determine their SER and SEFRA. In this way, the contribution of each component is examined in the context of its relationships with other components from various levels comprising the RA. The actual contribution of an RA component to SEFRA is not a direct reflection of its intrinsic value. The latter reflects how a component could contribute to SEFRA while the assessment reflects how it did contribute in the given context. In the present application, this approach allowed to effectively place the Messara Valley SES in the context of multi-level changes occurring over the study period, assess and explain their effects through the study of changes in the socio-ecological fit of the RAs formed over time and gain insights on the occurrence of and policy making for land degradation.

The principal insight concerns the role played by land degradation in shaping human responses in a land degradation-affected region. Throughout the study period, most land management decisions were taken without explicit concern for land degradation. Decisions were rather driven by economic and technological developments taking place at much higher levels [36-38]. Land degradation issues must, therefore, be placed in another perspective as they do not necessarily have priority locally. Responses, in the form of environmentally beneficial or detrimental land management practices, emerge and spread as actors pursue other goals, unless environmental resources start to become limiting. Regrettably, more often than not, once this happens, degradation has already considerably progressed.

A second insight concerns the intensity of territorialization processes, such as land management and other practices, which hold the RA components together but also determine the magnitude and importance of their effects. It is important to discover whether practices leading to environmental gains or losses were a necessary part of the respective responses. For example, in Messara, the use of modern agricultural equipment led to a runaway (plowing even more often and deeper) that was carried on further than was necessary to accomplish its purpose (increase of production), a clear indication of path dependency $[39,40]$. On the other hand, the expansion of irrigation is a necessary part of intensive crop management. Many local stakeholders share the view that the future fit of the Messara RA will depend on the sufficiency of irrigation water.

A third important insight is that modernization of agriculture does not lead to adverse environmental impacts across all cases. Expansion of olive groves has had significant positive effects in the study area, reinforcing the case for site-specific assessments and tailor-made, instead of "One Size Fits All", environmental policies [8,41]. The challenge is to manage resilience locally at times when major influences are exerted by processes exceedingly beyond the reach of the respective societies; e.g., the World Trade Organization negotiation rounds [42]. The insights gained by the kind of assessment carried out in the present study could be used to develop "Optimal" Response Assemblages". Based on the assessment of SEFRA over the study period, one can extrapolate the assessment into the future to assess the fit of RAs under one or more future scenarios. The assessment should be understood as a means of investigating various options, not as a bulletproof means to 'discover' a resilient SES in an unpredictable future.

The application of the methodology represents an interdisciplinary endeavor that poses significant conceptual, methodological and practical present and future research challenges. The successful application of integrated analytical approaches critically hinges on the adoption of common or compatible conceptual and theoretical frames and the transgression of disciplinary approaches to the study of socio-ecological problems. Future research may explore whether and how the non-reductionist assemblage ontology may serve as an integrative analytic able to accommodate, bring into dialogue and synthesize different epistemological, theoretical and methodological streams working together towards the analysis and explanation of multifaceted objects of analysis such as the response assemblages.

The analysis of RAs necessarily employs a variety of techniques from the Natural and the Social Sciences to assess the LLPs and synthesize them to obtain assessments of RAT, SER and SEFRA. Drawing on interdisciplinary conceptualizations, techniques for the synthesis of LLPs for different components (e.g., water resources and social capital) to obtain assessments of RAT, SER and SEFRA need to be developed. Moreover, the interplay between properties emerging from different components 
and the nature or the values of the individual components should be further explored, as well as their influence on the fit of the RA. In the present application, low land use diversity did not hinder adaptation since a single component (olive tree cultivation) proved sufficient for that purpose.

The ease of applying the methodology, the choice of assessment techniques and the validity, reliability and usefulness of the findings critically depend on the availability of qualitative and quantitative, primary and secondary data as well as expertise and the active involvement of stakeholders from various levels. More empirical applications in a variety of settings will reveal the strengths and weaknesses of the methodology and, most importantly, will demonstrate the advantages of the assemblage ontology for the analysis of complex socio-ecological problems such as land degradation compared to total system ontologies prevalent in most studies.

Acknowledgments: Research reported in this paper was carried out under project LEDDRA, funded by the Environment Programme, Management of Natural Resources, DG Research and Innovation. Grant Agreement No.: 243857 (1 April 2010-31 March 2014). The authors wish to thank Th. Kizos, Th. Iosifides, M. Metaxakis, A. Kandalepas and E. Stylianou for data sharing and fruitful discussions on the Messara socio-ecological system.

Author Contributions: V.D. carried out the synthesis of the analyses and wrote most of Section 3 and contibuted to Sections 1 and 4. H.B. conceived the study, contibuted to the analysis of social and economic data and and wrote Section 2 and most of Section 1 and partly 4. C.K.contibuted to the analysis of biophysical data and to the writing of Section 3.

Conflicts of Interest: The authors declare no conflict of interest. The founding sponsors had no role in the design of the study; in the collection, analyses, or interpretation of data; in the writing of the manuscript, and in the decision to publish the results.

\section{References}

1. Briassoulis, H. Governing desertification in Mediterranean Europe: The challenge of environmental policy integration in multi-level governance contexts. Land Degrad. Dev. 2011, 22, 313-325. [CrossRef]

2. Bajocco, S.; de Angelis, A.; Perini, L.; Ferrara, A.; Salvati, L. The impact of land use/land cover changes on land degradation dynamics: A Mediterranean case study. Environ. Manag. 2012, 49, 980-989. [CrossRef] [PubMed]

3. Kosmas, C.; Kairis, O.; Karavitis, C.; Ritsema, C.; Salvati, L.; Acikalin, S.; Alcalá, M.; Alfama, P.; Atlhopheng, J.; Barrera, J.; et al. Evaluation and selection of indicators for land degradation and desertification monitoring: Methodological approach. Environ. Manag. 2014, 54, 951-970. [CrossRef] [PubMed]

4. Mol, G.; Keesstra, S.D. Soil science in a changing world. Curr. Opin. Environ. Sustain. 2012, 4, $473-477$. [CrossRef]

5. Keesstra, S.D.; Bouma, J.; Wallinga, J.; Tittonell, P.; Smith, P.; Cerdà, A.; Montanarella, L.; Quinton, J.N.; Pachepsky, Y.; van der Putten, W.H.; et al. The significance of soils and soil science towards realization of the United Nations Sustainable Development Goals. SOIL 2016, 2, 111-128. [CrossRef]

6. Millennium Ecosystem Assessment. Ecosystems and Human Well-Being: Policy Responses; Island Press: Washington, DC, USA, 2005; Volume 3.

7. Reynolds, J.F.; Stafford-Smith, D.M. (Eds.) Global Desertification: Do Humans Cause Deserts? Dahlem Workshop Report 88; Dahlem University Press: Berlin, Germany, 2002.

8. Briassoulis, H. The Socio-ecological Fit of Human Responses to Environmental Degradation: An Integrated Assessment Methodology. Environ. Manag. 2015, 56, 1448-1466. [CrossRef] [PubMed]

9. Folke, C.; Carpenter, S.R.; Walker, B.; Scheffer, M.; Chapin, T.; Rockström, J. Resilience Thinking: Integrating Resilience, Adaptability and Transformability. Ecol. Soc. 2010, 15, 20. [CrossRef]

10. Lebel, L.; Nikitina, E.; Pahl-Wostl, C.; Knieper, C. Institutional Fit and River Basin Governance: A New Approach Using Multiple Composite Measures. Ecol. Soc. 2013, 18, 1. [CrossRef]

11. Folke, C.; Pritchard, L.; Berkes, F.; Colding, J.; Svedin, U. The Problem of Fit between Ecosystems and Institutions: Ten Years Later. Ecol. Soc. 2007, 12, 30. [CrossRef]

12. Haller, T.; Fokou, G.; Mbeyale, G.; Meroka, P. How fit turns into misfit and back: Institutional transformations of pastoral commons in African floodplains. Ecol. Soc. 2013, 18, 34. [CrossRef]

13. Lejano, R.P.; Shankar, S. The contextualist turn and schematics of institutional fit: Theory and a case study from Southern India. Policy Sci. 2013, 46, 83-102. [CrossRef] 
14. DeLanda, M. A New Philosophy of Society: Assemblage Theory and Social Complexity; Continuum: London, UK, 2006.

15. Briassoulis, H. Response assemblages and their socioecological fit: Reconceptualizing human responses to environmental degradation. Dialogues Hum. Geogr. 2017, in press.

16. Bonta, M.; Protevi, J. Deleuze and Geophilosophy: A Guide and Glossary; Edinburgh University Press: Edinburgh, UK, 2004.

17. DeLanda, M. Intensive Science and Virtual Philosophy; Continuum: London, UK, 2002.

18. Walker, B.; Holling, C.S.; Carpenter, S.R.; Kinzig, A.P. Resilience, Adaptability and Transformability in Social-Ecological Systems. Ecol. Soc. 2004, 9, 5. [CrossRef]

19. Folke, C.; Carpenter, S.; Elmqvist, T.; Gunderson, L.; Holling, C.S.; Walker, B. Resilience and sustainable development: Building adaptive capacity in a world of transformations. Ambio 2002, 31, 437-440. [CrossRef] [PubMed]

20. Walker, B.; Gunderson, L.; Kinzig, A.; Folke, C.; Carpenter, S.; Schultz, L. A handful of heuristics and some propositions for understanding resilience in social-ecological systems. Ecol. Soc. 2006, 11, 13. [CrossRef]

21. Resilience Alliance. Assessing Resilience in Social-Ecological Systems; Workbook for Scientists, Version 1.1; Resilience Alliance: Stockholm, Sweden, 2007.

22. Scheffer, M.; Carpenter, S.R.; Lenton, T.M.; Bascompte, J.; Brock, W.; Dakos, V.; van de Koppel, J.; van de Leemput, I.A.; Levin, S.A.; van Nes, E.H.; et al. Anticipating critical transitions. Science 2011, 338, 344-348. [CrossRef] [PubMed]

23. Berkes, F.; Colding, J.; Folke, C. Navigating Social-Ecological Systems: Building Resilience for Complexity and Change; Cambridge University Press: Cambridge, UK, 2003.

24. Cabell, J.F.; Oelofse, M. An indicator framework for assessing agroecosystem resilience. Ecol. Soc. 2012, 17, 18. [CrossRef]

25. Cumming, G.S.; Barnes, G.; Perz, S.; Schmink, M.; Sieving, K.E.; Southworth, J.; Binford, M.; Holt, R.D.; Stickler, C.; Van Holt, T.; et al. An Exploratory Framework for the Empirical Measurement of Resilience. Ecosystems 2005, 8, 975-998. [CrossRef]

26. Janssen, M.A.; Bodin, F.; Anderies, J.M.; Elmqvist, T.; Ernstson, H.; McAllister, R.R.J.; Olsson, P.; Ryan, P. Towards a network perspective on the resilience of social-ecological systems. Ecol. Soc. 2006, 11, 15. [CrossRef]

27. Ostrom, E. Understanding Institutional Diversity; Princeton University Press: Princeton, NJ, USA, 2005.

28. Rosenfeld, J.S. Functional redundancy in ecology and conservation. Oikos 2002, 98, 156-162. [CrossRef]

29. Stirling, A. A general framework for analysing diversity in science, technology and society. Interface 2007, 4, 707-719. [CrossRef] [PubMed]

30. Cumming, G.S.; Collier, J. Change and Identity in Complex Systems. Ecol. Soc. 2005, 10, 29. [CrossRef]

31. Epstein, G.; Vogt, J.M. Missing ecology: Integrating ecological perspectives with the social-ecological system framework. Int. J. Commons 2011, 7, 432-453. [CrossRef]

32. Karamesouti, M.; Detsis, V.; Kounalaki, A.; Vasiliou, P.; Salvati, L.; Kosmas, C. Land-use and land degradation processes affecting soil resources: Evidence from a traditional Mediterranean cropland (Greece). CATENA 2015, 132, 45-55. [CrossRef]

33. Alados, C.L.; Errea, P.; Gartzia, M.; Saiz, H.; Escós, J. Positive and Negative Feedbacks and Free-Scale Pattern Distribution in Rural-Population Dynamics. PLoS ONE 2014, 9, e114561. [CrossRef] [PubMed]

34. Kosmas, C.; Karamesouti, M.; Kounalaki, K.; Detsis, V.; Vassiliou, P.; Salvati, L. Land degradation and long-term changes in agro-pastoral systems: An empirical analysis of ecological resilience in Asteroussia-Crete (Greece). CATENA 2016, 147, 196-204. [CrossRef]

35. Kizos, T.; Detsis, V.; Iosifides, T.; Metaxakis, M. Social capital and social-ecological resilience in the Asteroussia Mountains, Southern Crete, Greece. Ecol. Soc. 2014, 19, 40. [CrossRef]

36. Lambin, E.F.; Meyfroidt, P. Land use transitions: Socio-ecological feedback versus socio-economic change. Land Use Policy 2010, 27, 108-118. [CrossRef]

37. Iosifides, T.; Politidis, T. Socio-economic dynamics, local development and desertification in western Lesvos, Greece. Local Environ. 2005, 10, 487-499. [CrossRef]

38. Kizos, T.; Koulouri, M. Economy, Demographic Changes and Morphological Transformation of the Agri-Cultural Landscape of Lesvos, Greece. Hum. Ecol. Rev. 2005, 21, 183-192. 
39. Wilson, G.A. Community resilience: Path dependency, lock-in effects and transitional ruptures. J. Environ. Plan. Manag. 2014, 57,1-26. [CrossRef]

40. Wilson, G.A.; Kelly, C.L.; Briassoulis, H.; Ferrara, A.; Quaranta, G.; Salvia, R.; Detsis, V.; Curfs, M.; Cerda, A.; El-Aich, A.; et al. Social memory and the resilience of communities affected by land degradation. Land Degrad. Dev. 2017, 28, 383-400. [CrossRef]

41. Detsis, V. Placing land degradation and biological diversity decline in a unified framework: Methodological and conceptual issues in the case of the north Mediterranean region. Land Degrad. Dev. 2010, 21, 413-422. [CrossRef]

42. Kelly, C.; Ferrara, A.; Wilson, G.A.; Ripullone, F.; Nolè, A.; Harmer, N.; Salvati, L. Community resilience and land degradation in forest and shrubland socio-ecological systems: Evidence from Gorgoglione, Basilicata, Italy. Land Use Policy 2015, 46, 11-20. [CrossRef]

(c) 2017 by the authors. Licensee MDPI, Basel, Switzerland. This article is an open access article distributed under the terms and conditions of the Creative Commons Attribution (CC BY) license (http://creativecommons.org/licenses/by/4.0/). 